\begin{tabular}{|c|l|}
\hline Title & $\begin{array}{l}\text { Ionospheric disturbances of the 2007 Bengkulu and the 2005 Nias earthquakes, Sumatra, observed with a regional GPS } \\
\text { network }\end{array}$ \\
\hline Author(s) & Cahyadi, Mokhamad Nur; Heki, Kosuke \\
\hline Citation & $\begin{array}{l}\text { Journal of Geophysical Research: Space Physics, 118(4), 1777-1787 } \\
\text { https:/doi.org/_0.1002/3ra.50208 }\end{array}$ \\
\hline Issue Date & 2013_04 \\
\hline Doc URL & http://hdl.handle.net/2115/54560 \\
\hline Rights & Copyright [2013] A merican Geophysical Union. \\
\hline Type & article \\
\hline File Information & Cahyadi_Heki_JGR2013.pdf \\
\hline
\end{tabular}

Instructions for use 


\title{
Ionospheric disturbances of the 2007 Bengkulu and the 2005 Nias earthquakes, Sumatra, observed with a regional GPS network
}

\author{
Mokhamad Nur Cahyadi ${ }^{1,2}$ and K. Heki ${ }^{1}$ \\ Received 11 July 2012; revised 8 February 2013; accepted 28 February 2013.
}

[1] We studied ionospheric disturbances associated with the two large earthquakes in Sumatra, Indonesia, namely, the 2007 Bengkulu and the 2005 Nias earthquakes, by measuring the total electron contents (TEC) using a regional network of global positioning system (GPS) receivers. We first focus on coseismic ionospheric disturbances (CIDs) of the Bengkulu earthquake $\left(M_{w} 8.5\right)$. They appeared 11-16 min after the earthquake and propagated northward as fast as $\sim 0.7 \mathrm{~km} / \mathrm{s}$, consistent with the sound speed at the ionospheric F layer height. Resonant oscillation of TEC with a frequency of $\sim 5 \mathrm{mHz}$ continued for at least $30 \mathrm{~min}$ after the earthquake. The largest aftershock $\left(M_{w} 7.9\right)$ also showed clear CIDs similar to the main shock. A CID propagating with the Rayleigh wave velocity was not observed, possibly because the station distribution did not favor the radiation pattern of the surface waves. This earthquake, which occurred during a period of quiet geomagnetic activity, also showed clear preseismic TEC anomalies similar to those before the 2011 Tohoku-Oki earthquake. The positive and negative anomalies started 30-60 min before the earthquake to the north and the south of the fault region, respectively. On the other hand, we did not find any long-term TEC anomalies within 4-5 days before the earthquake. Co- and preseismic ionospheric anomalies of the 2005 Nias earthquake $\left(M_{w} 8.6\right)$ were, however, masked by strong plasma bubble signatures, and we could not even discuss the presence or absence of CIDs and preseismic TEC changes for this earthquake.

Citation: Cahyadi, M. N., and K. Heki (2013), Ionospheric disturbances of the 2007 Bengkulu and the 2005 Nias earthquakes, Sumatra, observed with a regional GPS network, J. Geophys. Res. Space Physics, 118, doi:10.1002/jgra.50208.

\section{Introduction}

[2] Ionospheric total electron content (TEC) is easily derived from the phase differences of the two L-band carrier waves of the global positioning system (GPS) satellites. In addition to the ionospheric disturbances of solar-terrestrial origin, past GPS-TEC studies have revealed various kinds of disturbances excited by phenomena in the solid earth, e.g., volcanic eruption [Heki, 2006], launches of ballistic missiles [Ozeki and Heki, 2010], mine blasts [Calais et al., 1998], and so on. Among others, many studies have been done for coseismic ionospheric disturbances (CIDs), the variation of the ionospheric electron density induced by acoustic and gravity waves generated by crustal movements associated with large earthquakes [e.g., Calais et al., 1998; Afraimovich et al., 2001; Heki and Ping, 2005; Astafyeva et al., 2009; Astafyeva and Heki, 2011; Tsugawa et al., 2011].

\footnotetext{
All supporting information may be found in the online version of this article. Japan.

${ }^{1}$ Department of Natural History Sciences, Hokkaido University, Sapporo,

${ }^{2}$ Geomatics Engineering Department, Institut Teknologi Sepuluh Nopember (ITS), Surabaya, Indonesia.

Corresponding author: M. N. Cahyadi, Department of Natural History Sciences, Hokkaido University, Sapporo, Japan. (cahyadi_its@mail.sci. hokudai.ac.jp)

(C)2013. American Geophysical Union. All Rights Reserved. 2169-9380/13/10.1002/jgra.50208
}

[3] The 2005 Nias earthquake $\left(M_{w}\right.$ 8.6) [Briggs et al., 2005 ] and the 2007 Bengkulu earthquake $\left(M_{w} 8.5\right)$ [Gusman et al., 2010] occurred as mega-thrust earthquakes in the Sunda Arc in Sumatra as large aftershocks of the 2004 great Sumatra-Andaman earthquake $\left(M_{w}\right.$ 9.2) [Banerjee et al., 2005], between the subducting Australian Plate and the overriding Sundaland Plates [Simons et al., 2007]. The Nias earthquake occurred $\sim 3$ months after the main shock (16:09:36 UTC, 28 March 2005) on a fault segment in the southeastern extension of the 2004 earthquake rupture area. It ruptured the plate boundary, spanning $\sim 400 \mathrm{~km}$ along the trench, with $>11 \mathrm{~m}$ of fault slip. Uplift reaching $3 \mathrm{~m}$ occurred along the trench-parallel belts on the outer-arc islands [Briggs et al., 2006]. The Bengkulu earthquake (11:10:26 UTC, 12 September 2007) occurred to the west of southern Sumatra $\sim 3$ years after the 2004 SumatraAndaman earthquake. It ruptured the plate interface approximately $220-240 \mathrm{~km}$ in length and $60-70 \mathrm{~km}$ in width along the Sunda arc. About one half day later, an aftershock of $M_{w} 7.9$ followed.

[4] Although the CIDs of the 2004 Sumatra-Andaman earthquake have been investigated in detail by Heki et al. [2006], those of these two major aftershocks have not been studied yet. In fact, they are the two largest earthquakes whose ionospheric disturbances have not been studied in spite of the availability of GPS data. Continuous GPS stations in Sumatra and smaller islands along the Sunda Trench have been operated as the Sumatra GPS Array (SUGAR) 
network, which is designed, constructed, and operated by members of the Tectonics Observatory at Caltech and the Indonesian Institute of Sciences (LIPI). We also used some stations of the International GNSS Service (IGS) network. Here, we investigate CIDs associated with these earthquakes and compare them with past earthquakes.

[5] Acoustic waves are excited by vertical movements of the ground or the sea surface. They propagate upward and reach the $\mathrm{F}$ layer height of the ionosphere in $10 \mathrm{~min}$ or so. There the waves make irregularities of electron density, which are detected as CIDs [Heki and Ping, 2005; Rolland et al., 2011a]. Astafyeva et al. [2009] identified two distinct propagation velocities of such acoustic waves after the Hokkaido-Toho-Oki earthquake of 4 October 1994 , i.e., the slow component of $\sim 1 \mathrm{~km} / \mathrm{s}$ and the fast component of $\sim 4 \mathrm{~km} / \mathrm{s}$. They inferred that they were excited by coseismic vertical crustal movement and by the Raleigh surface wave, respectively. In the Tokachi-Oki earthquake of 23 September 2003, Heki and Ping [2005] found N-S asymmetry, i.e., CIDs are clearly seen only on the southern side of the epicenter. They suggested that geomagnetic field is responsible for such directivity. It would be important if such velocities and directivity were also seen in the 2007 Bengkulu and 2005 Nias earthquakes.

[6] Choosakul et al. [2009] found that the acoustic resonance characterized by the TEC oscillation with periods of 3.7 and $4.5 \mathrm{~min}$ followed the CID of the 2004 Sumatra-Andaman earthquake, and lasted for hours. 2011 Saito et al. [2011] and Rolland et al. [2011b] also reported similar resonant oscillation after the 2011 Tohoku-Oki earthquake. In this earthquake, the GPS network also detected another component, i.e., the internal gravity wave propagating with a speed $\sim 0.3 \mathrm{~km} / \mathrm{s}$ [Tsugawa et al., 2011]. Because of the large magnitudes of the 2007 Bengkulu and 2005 Nias earthquakes, we can expect to detect similar signals after these earthquakes.

[7] Among various kinds of earthquake precursors reported so far [Rikitake, 1976], electromagnetic phenomena have been explored worldwide, e.g., electric currents in the ground [Uyeda and Kamogawa, 2008], a propagation anomaly of VLF [Molchanov and Hayakawa, 1998] and VHF [Moriya et al., 2010] radio waves, and satellite observations [Némec et al., 2008]. Heki [2011] suggested that mega-thrust earthquakes are immediately preceded by the enhancement of TEC by analyzing recent M9 class interplate thrust earthquakes, i.e., the 2004 Sumatra-Andaman and the 2008 Maule earthquakes, in addition to the 2011 Tohoku-Oki earthquake. The possible precursors reported by Heki [2011] have obvious temporal and spatial correlations with earthquakes and clear magnitude dependence, although physical processes have not been identified yet. As the second focus of the present study, we examine if similar precursory TEC anomalies occurred before the 2007 Bengkulu and the 2005 Nias earthquakes. Apart from such short-term precursors, there have been reports of TEC anomalies in a longer term, 3-5 days before earthquakes [e.g., Liu et al., 2001; 2009]. We also briefly examine if this type of anomaly preceded the 2007 Bengkulu earthquake. Thus, this paper presents the first comprehensive GPS-TEC case study treating both co- and preseismic ionospheric disturbances of specific mega-thrust earthquakes.

\section{GPS Data Analysis}

[8] Because the GPS satellites are located $\sim 20,000 \mathrm{~km}$ above the earth's surface, their microwave signals propagate through the ionosphere before reaching ground receivers. GPS satellites transmit in the two L-band carrier waves $(\sim 1.2$ and $\sim 1.5 \mathrm{GHz})$. For accurate positioning, we remove ionospheric delays by making the ionosphere-free linear combinations of the two carrier phases. For ionospheric studies, we derive TEC from the differences of the phases of the two frequencies, often called the ionospheric linear combination.

[9] The raw data have been downloaded from the data centers of SUGAR and IGS. The sampling interval of the SUGAR stations was $2 \mathrm{~min}$, four times as long as the standard sampling interval (e.g., in IGS) of $30 \mathrm{~s}$. Data from 22 and 14 SUGAR sites were available on the days when the 2007 Bengkulu and the 2005 Nias earthquakes occurred, respectively. In addition, we also use three IGS stations in northern Sumatra (samp), Java (bako), Indonesia, and Singapore (ntus). To analyze the behaviors of TEC in the period without large earthquakes, we also downloaded 4 months' worth (including the 2007 Bengkulu earthquake) of GPS raw data of the biti station in Nias Island.

[10] To investigate spatial characteristics of the disturbances, e.g., propagation speed of such disturbances, we calculate ionospheric piercing point (IPP) of line-of-sights assuming a thin layer of ionosphere at altitudes $\sim 300 \mathrm{~km}$. Then their projections onto the ground, i.e., sub-ionospheric points (SIP), are derived. SIPs are often located more than $1000 \mathrm{~km}$ away from the GPS stations depending on the elevation angles of the satellites. At the same time, penetration angles of the line-of-sight vectors to the hypothetical thin ionosphere are calculated. Such angles are used in converting anomalies in slant TEC to those in vertical TEC.

[11] TEC shows apparent variations by the motion of the satellite in the sky. It also changes by diurnal variation of the solar zenith angle and long-term disturbances such as large-scale traveling ionospheric disturbances (LSTID). In order to eliminate such long-term variations and isolate CIDs, high-pass filters are often used. Here we employ polynomials of time with degree up to 6 , and study residuals from these polynomials to study CIDs. On the other hand, preseismic TEC enhancement has a longer time scale. Thus, we employed the procedure of Ozeki and Heki [2010] and Heki [2011], in which they detected TEC anomalies with longer time scales (up to an hour) assuming that the temporal changes of vertical TEC obey cubic polynomials of time.

\section{TEC Changes in the 2007 Bengkulu Earthquake}

\subsection{CID Amplitudes and Waveforms}

[12] First we investigate the TEC responses to the Bengkulu earthquake 2007. In Figure 1, we show raw slant TEC time series 9-13 UT recorded by all the satellites visible from the msai station in Sibelut Island. For the five satellites, 4, 8, 25, 27, and 28, clear CIDs appear after the earthquake, with time lags of 11-16 $\mathrm{min}$, the time needed for acoustic waves to travel from the surface to the IPP. The slant TEC fluctuations have amplitudes of $0.4-1.5$ TECU (total electron content unit, 1 TECU $=1016 \mathrm{el} \mathrm{m}^{-2}$ ) and periods of 4-5 $\mathrm{min}$. 


\section{CAHYADI AND HEKI: IONOSPHERIC DISTURBANCES OF BENGKULU EARTHQUAKE}

(a)

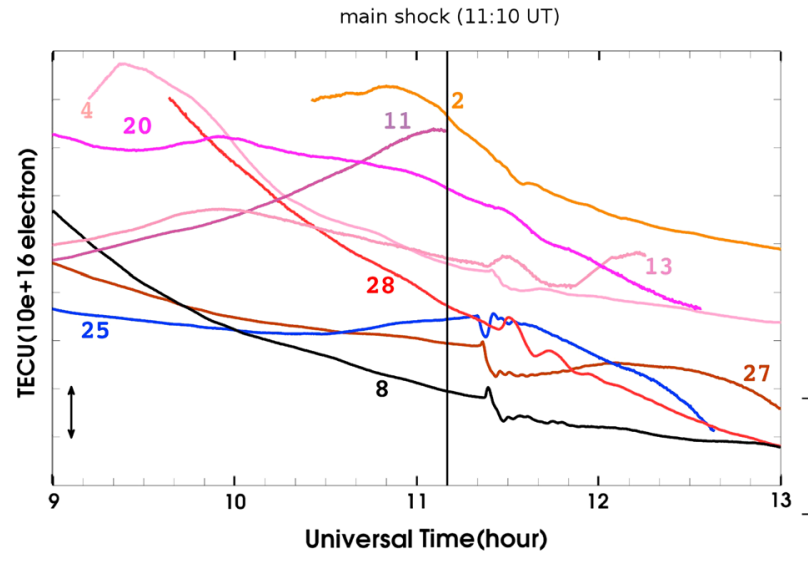

(b)

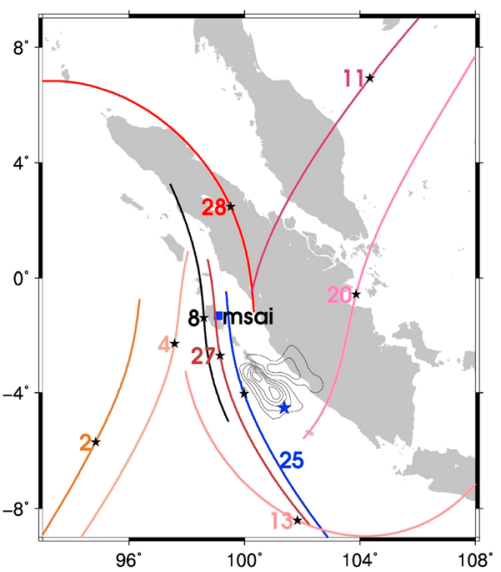

Figure 1. (a) Time series 9.00-13.00 UT of raw slant TEC changes observed at the msai station (position shown in Figure 1b) with nine GPS satellites. The black vertical line indicates the occurrence of the 2007 Bengkulu earthquake (11:10 UT). CIDs are seen 11-16 min after the earthquake. (b) Trajectories of SIP for satellites shown in Figure 1a. On the trajectories, small black stars are SIP at 11:10, and the contour shows the coseismic uplift (contour interval: $0.2 \mathrm{~m}$ ) of this earthquake [Gusman et al., 2010]. The large blue star shows the epicenter.

[13] Astafyeva and Heki [2009] compared the CID waveforms of the 2006 and 2007 large earthquakes that occurred with reverse and normal mechanisms, respectively, in the Kuril Islands. They found that a CID starts with positive (negative) changes, i.e., TEC increase (decrease), suggesting that compression (rarefaction) atmospheric pulse led the acoustic wavefront in the 2006 (2007) earthquake. Acoustic waves led by the rarefaction are unstable but might reach the ionosphere when the earthquake is large enough (the 2007 event exceeded $M_{w} 8$ ). Figure 1 suggests that the CID of the 2007 Bengkulu earthquake started with a positive polarity, which is consistent with the reverse faulting mechanism of this earthquake. Satellite 25 appears to show a negative initial change, but this might be due to the low sampling rate, i.e., the narrow positive peak failed to be sampled (see also Figure 2c).

[14] For satellites 8, 25, 27, and 28, slant TEC time series observed at 9 to 10 GPS stations are plotted in Figure 2. These time series were obtained as the residuals from the best-fit degree- 6 polynomials used as the high-pass filter. The disturbances are seen to start with positive anomalies in most cases. Satellites 25 and 27 were both in the southern sky during this time interval, moving from north to south. The disturbances by both of these satellites were similar in waveform, but the amplitudes that were seen in satellite 25 were larger. As inferred from the propagation velocity (see the next section), the CID is of acoustic wave origin, and its wavefront tilts from the epicenter outward near the epicenter [see, e.g., Heki et al., 2006, Figure 2]. The larger CID with satellite 25 would reflect shallower angles between the line-of-sight and the wave front.

[15] Satellite 28 was in the northern sky, and CID amplitudes are considerably small in the stations to the north of the epicenter. In the geometry of satellite 28 , the line-of-sight penetrates the wavefront in a deep angle, and the positive and negative electron density anomalies tend to cancel each other. In Figure 2c (satellite 25), two stations, ntus and bsat, show signals significantly smaller than the others. The small signal at ntus simply reflects the long distance of its SIP from the source (Figure 2d). The small signal at bsat, closer to the source than other sites, would have come from the deep angle of the line-of-sight penetration with the front. The northward beam of the CID in the southern hemisphere [Heki and Ping, 2005] may have further reduced the signal at bsat.

[16] As shown in Figure 2c, satellite 25 shows the largest CID at the samp station, northern Sumatra. In addition to the line-of-sight and wave front geometry, this also reflects the fact that at samp, an IGS station, the sampling interval is $30 \mathrm{~s}$, one fourth of other SUGAR stations. The SUGAR stations would have simply missed the highest peak of CID. In Figure 3a, we compare satellite 25 -samp time series with the original sampling interval and those arbitrarily resampled with the 2 min intervals. The latter peak is much lower ( $\sim 3$ TECU) than the former ( $\sim 5$ TECU).

[17] In Figure 3, the samp station shows clear monochromatic oscillation of TEC lasting for half an hour. Spectral analysis (by the Blackman-Tukey method) suggests that its period is close to $\sim 4.4 \mathrm{mHz}$, one of the atmospheric resonance frequencies often observed after large earthquakes [Choosakul et al., 2009; Saito et al., 2011; Rolland et al., 2011b]. Figure 3 also shows that such oscillation becomes ambiguous with the lower sampling rate. Thus, it is recommended to use sampling intervals of $30 \mathrm{~s}$ or less for detailed studies of ionospheric disturbances by earthquakes.

\subsection{Propagation Speeds}

[18] Apparent velocity of CID was calculated from the arrival time differences at points of various distances from the center of crustal uplift. Travel time diagrams based on the data from the four satellites are shown in Figure 4. There the short-term slant TEC anomalies shown in Figure 2 are expressed in colors painted on curves showing the relationship between the travel time (horizontal axis) and focal distance (vertical axis). Slopes of the black lines connecting the peak positive TEC anomalies (red part) correspond to the 
(a)

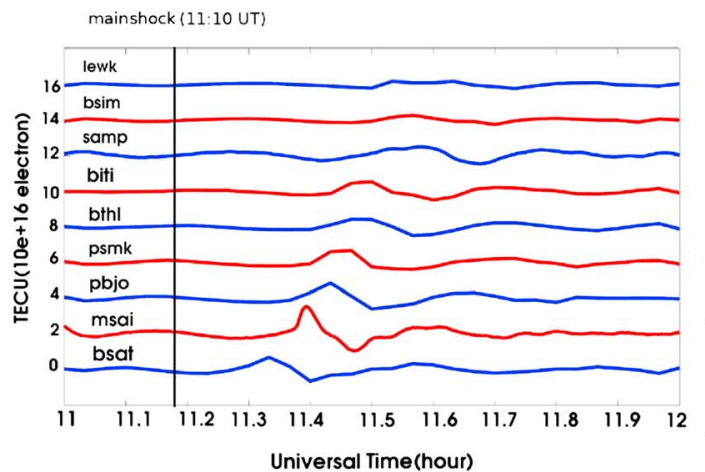

(c)

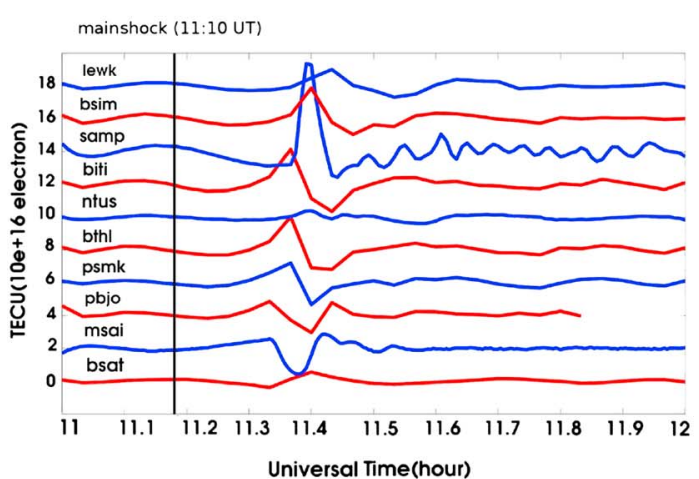

(e)

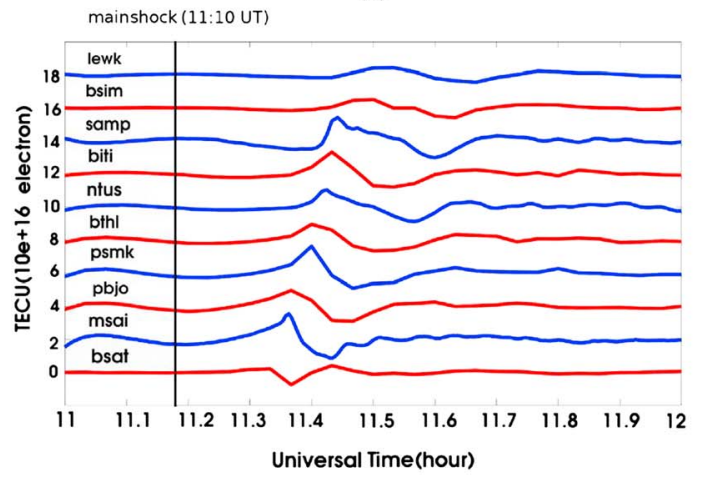

(g)

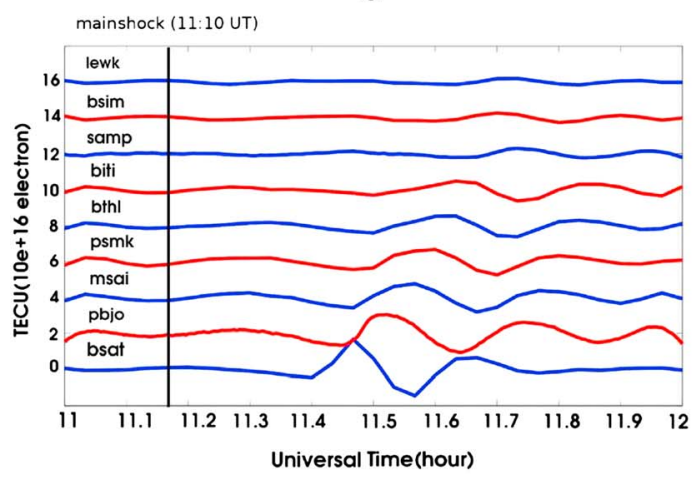

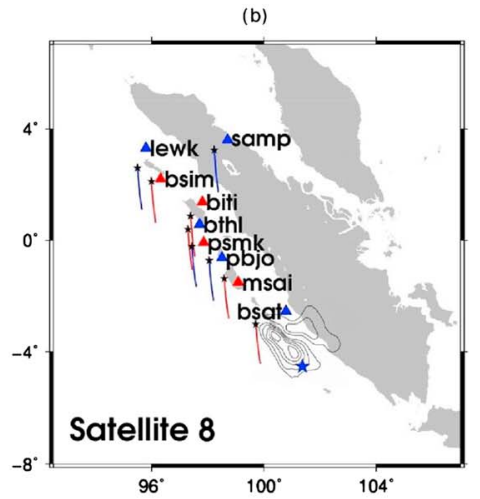

(d)

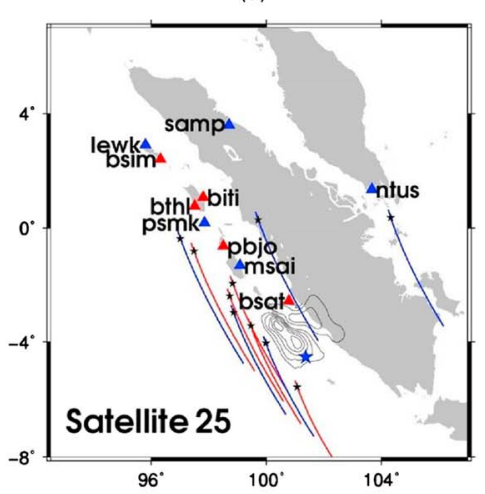

(f)
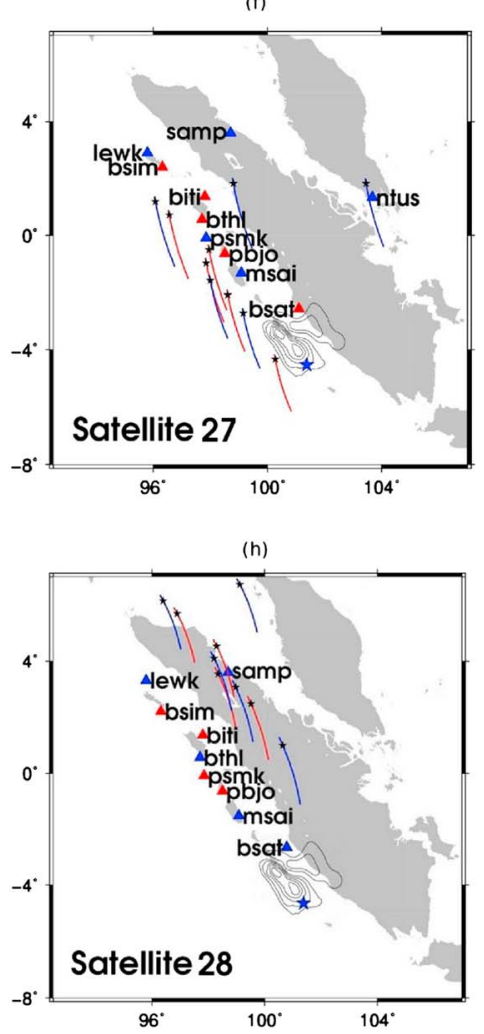

Figure 2. Time series $11.00-12.00$ UT of slant TEC changes and their SIP trajectories by four satellites, i.e., satellites $(\mathrm{a}, \mathrm{b}) \mathrm{8}$, (c, d) 25, (e, f) 27, and (g, h) 28. The black vertical lines in the time series (Figures 2a, 2c, 2e, and 2g) indicate the time of the 2007 Bengkulu earthquake. On the trajectories (Figures 2b, 2d, 2f, and 2h), small black stars are SIP at 11:10 UT. The contour shows the uplift and the blue star shows the epicenter (see Figure 1 caption). The triangles are the GPS stations, and their colors (blue or red) coincide with those of the SIP track and TEC time series. 


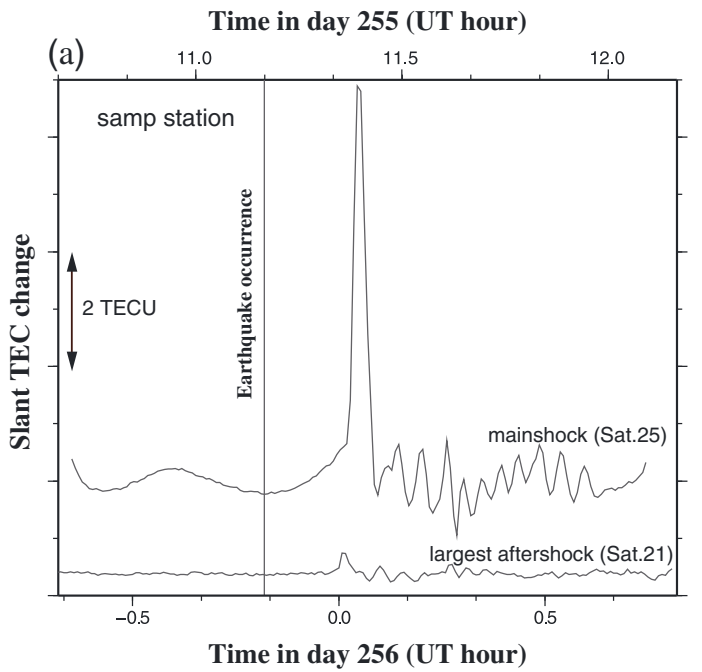

(b)

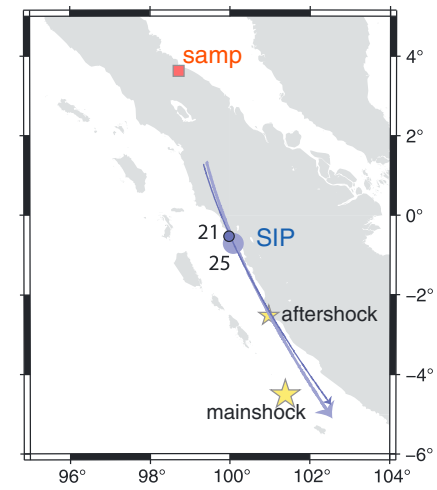

Figure 3. Comparison of the CIDs recorded at the samp station for satellite 25 in 2 min sampling (light gray) and $30 \mathrm{~s}$ sampling (black). Power spectrum of the time series $(30 \mathrm{~s})$ between 11.5 and 12.0 are shown to the right. The observed peak $(\sim 5 \mathrm{mHz})$ is close to one of the two atmospheric resonance frequencies indicated by vertical lines $(3.7$ and $4.4 \mathrm{mHz})$.

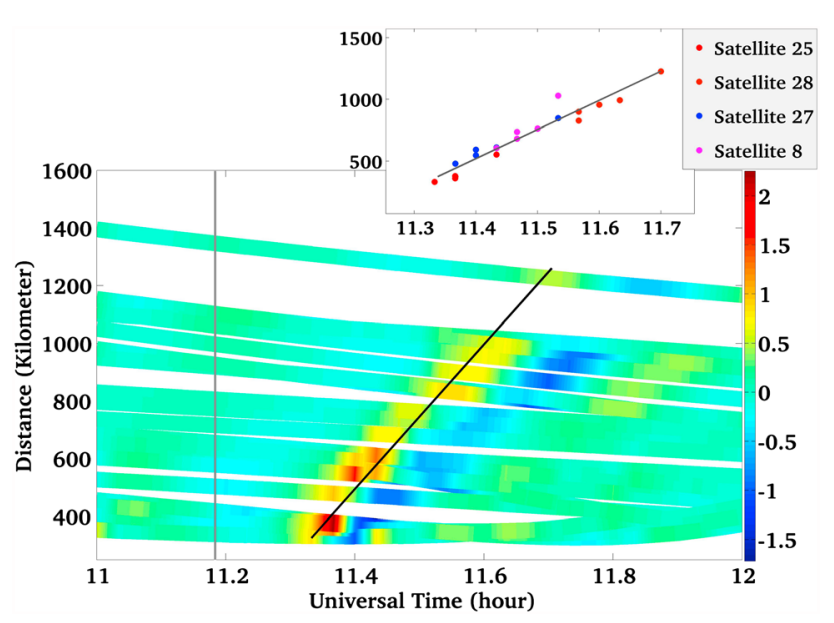

Figure 4. Travel-time diagram of the 2007 Bengkulu earthquake CID based on the data from satellites 8, 25, 27, and 28. Distances are measured from the center of the uplift region (contour map in Figure 1b) rather than the epicenter. The apparent velocity is $0.69 \mathrm{~km} / \mathrm{s}$ with the $1 \sigma$ error of $\pm 0.04 \mathrm{~km} / \mathrm{s}$. The gray vertical line indicates the occurrence of the earthquake (11:10 UT). The inset shows the arrival times of the maximum positive TEC anomalies for different satellites, for which linear regression has been performed.

apparent velocity of CID. The propagation velocity derived using all the four satellites with the least-squares method is $0.69 \pm 0.04 \mathrm{~km} / \mathrm{s}(1 \sigma)$ (Figure 4).

[19] Astafyeva et al. [2009] showed that CID has two distinct velocity components, i.e., the fast component propagating with the velocity of the Rayleigh surface wave (3-4 km/s) and the slow component propagating with the sound velocity $(0.6-1.0 \mathrm{~km} / \mathrm{s})$. The velocity obtained in this study clearly corresponds to the latter. The GPS stations are distributed along the arc, i.e., in the direction corresponding to the node in the radiation pattern of the Rayleigh surface wave. The absence of the Rayleigh surface wave signatures would be due to their small amplitude coming from such geometric conditions. There is no clear gravity wave signature in Figure 4.

[20] Heki and Ping [2005] demonstrated N-S asymmetry of the CID propagation, i.e., a CID hardly propagates northward because geomagnetism allows only oscillation of ionospheric electrons in the field-aligned direction in the $\mathrm{F}$ layer. This would reverse in the southern hemisphere, i.e., southward CID could be much smaller than northward CID in the 2007 Bengkulu earthquake. Unfortunately, we could not confirm this adequately because most of the SUGAR stations are located to the north of the fault. We just mention here that there is one station, mlkn, on Enggano Island, south of the epicenter, and it showed a much smaller CID amplitude than the stations to the north did (not shown in Figure 2).

\subsection{Preseismic Ionospheric Anomalies \\ 3.3.1. Long-term Anomalies}

[21] It has been suggested that the amplitudes of diurnal variations of TEC significantly decreased 3-4 days before the 1999 Chi-chi (Taiwan) earthquake [Liu et al., 2001] and 4-6 days before the 2008 Wenchuan (China) earthquake [Liu et al., 2009]. Based on statistical analyses, Le et al. [2011] suggested that such preseismic anomalies tend to appear 1-4 days before earthquakes, with a higher probability before larger and shallower earthquakes. On the other hand, Dautermann et al. [2007] analyzed 2003-2004 data in southern California and did not find any statistically significant correlation between TEC anomalies and earthquake occurrences.

[22] Here we estimated the hourly vertical TEC over a 1 month period including the 2007 Bengkulu earthquake using the GPS-TEC data at the biti station in Nias Island, following the method of Astafyeva and Heki [2011]. We did not use the global ionospheric model (GIM) because its spatial resolution is not sufficiently high [Mannucci et al., 1998]. We show the results over 18 days in Figure 5. 
CAHYADI AND HEKI: IONOSPHERIC DISTURBANCES OF BENGKULU EARTHQUAKE

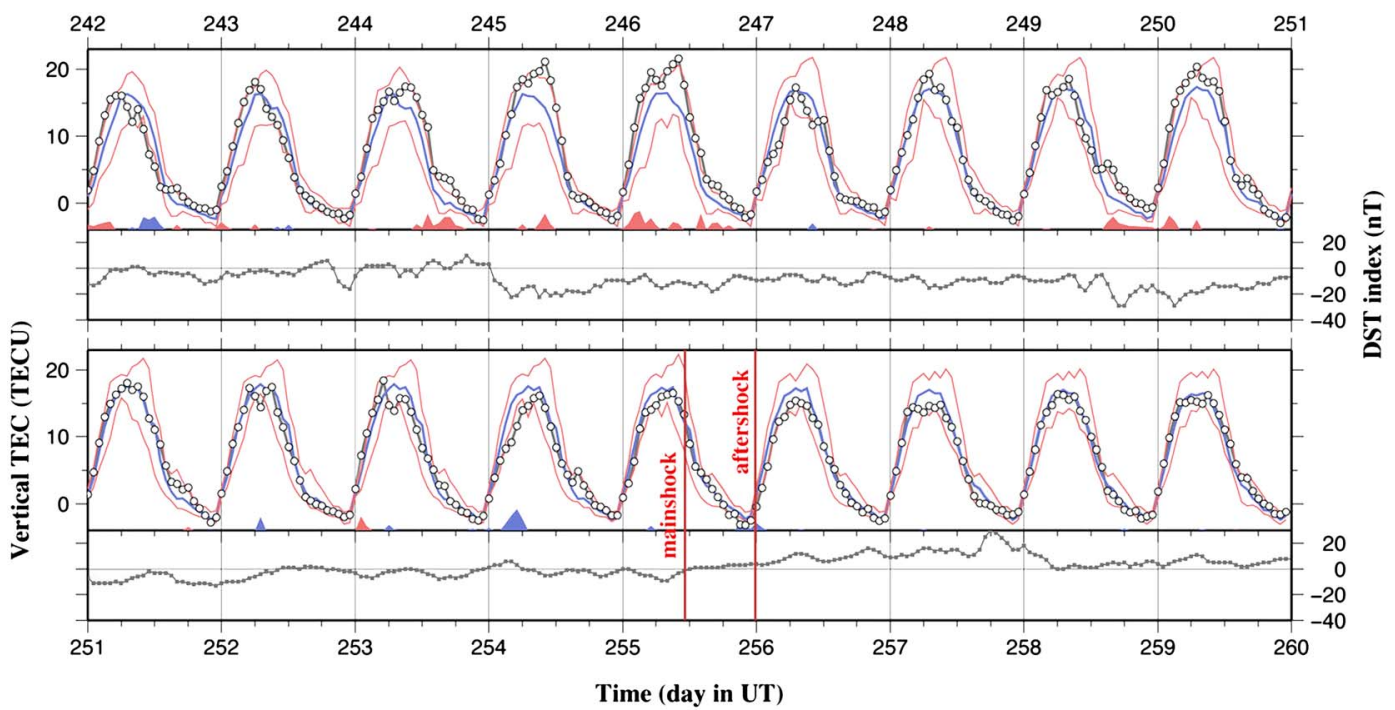

Figure 5. Time series of absolute vertical TEC (open circles connected with black lines) at the biti GPS station in Nias Island, over 15 days including the 12 September 2007 Bengkulu earthquake (day of the year 255 in UT, thick vertical line). Thick black curve shows the median of the preceding 15 days with upper and lower bounds of natural variability (taken 1.5 times as far from median as quartiles) shown by thinner curves. Red and blue shades at the bottom show the amount of positive and negative anomalies (amount above/below the upper/lower bounds of natural variability). There are positive anomalies in days 245-246 and days 249-250, and they are possibly related to geomagnetic disturbances on days 245 and 249 , respectively, as seen in the Dst indices.

Positive and negative anomalies exceeding natural variability were detected using a method similar to the one used in past studies (i.e., deviations larger than 1.5 times of the quartile from the median of the last 15 days are judged as anomalous). Diurnal variations are fairly regular. Occasional positive TEC anomalies occur (e.g., days 245, 246, and 250) shortly after geomagnetic disturbances shown as the disturbance storm time (Dst) indices (see Figure S1 for the indices in a larger time window). This index shows the average change of the horizontal component of geomagnetic field sat multiple magnetometers near the magnetic equator.

[23] During 1-4 days before the main shock (days 251-254), TEC mostly remained normal, with just a short and small negative anomaly on the previous day. The same situation was found for the $2010 M_{w} 8.8$ Chile (Maule) earthquake. Yao et al. [2012] reported that no significant long-term TEC anomalies preceded the 2010 Maule earthquake. According to the statistical study [Le et al., 2011], larger earthquakes tend to be preceded by clearer long-term TEC anomalies. Hence, the absence of the clear long-term TEC precursors before the 2007 Bengkulu and the 2010 Maule earthquakes raises a serious question about the existence of such long-term anomalies. 3.3.2. Short-term Anomalies

[24] Heki [2011] showed that a positive TEC anomaly started 60-40 min before the 2011 Tohoku-Oki earthquake, and suggested that a similar anomaly preceded the other two M9 class mega-thrust earthquakes, i.e., the 2004 Sumatra Andaman and the 2010 Maule earthquakes. Although the 2007 Bengkulu earthquake is somewhat smaller in magnitude, it is worth studying if a similar TEC anomaly occurred prior to the earthquake.

[25] In Figure 6, we show raw slant TEC time series over a $4 \mathrm{~h}$ period before and after the earthquake at seven GPS stations for satellites 25,27 and 8 . We derived reference curves following Ozeki and Heki [2010] and Heki [2011], i.e., modeling the vertical TEC as a cubic polynomial of time. We excluded the time interval 10.0-11.4 UT, which are possibly influenced by CIDs and preseismic anomalies, in estimating the models. Preseismic ionospheric anomalies, similar to those reported in Heki [2011], seem to exist. Their onset time varies from $\sim 30 \mathrm{~min}$ (lnng in Figure $6 \mathrm{c}$ ) to $\sim 60 \mathrm{~min}$ (biti in Figure $6 \mathrm{a}$ ) before the earthquake. The anomalies are dominated by increases in TEC, with smaller amounts of decrease seen in southern stations. The largest increase is $1-2$ TECU in vertical TEC, which is about $10 \%$ of the background value (Figure 5).

[26] The enhanced TEC anomalies recover after CIDs, and this can be understood as the combined result of physical and/or chemical processes, i.e., the mixing of ionosphere by acoustic waves and recombination of ions transported downward [Saito et al., 2011; Kakinami et al., 2012]. In order to see its influence, we changed the end of the exclusion intervals to $12.4 \mathrm{UT}$ (i.e., $1 \mathrm{~h}$ later than the nominal interval), and found that the results are robust against such changes. Figure 7 indicates snapshots of geographical distribution of TEC anomalies at three epochs, $1 \mathrm{~h}, 20 \mathrm{~min}$, and $1 \mathrm{~min}$ before the earthquake. The anomalies appear to have started $\sim 60 \mathrm{~min}$ before the earthquake and to have expanded on the northern side of the fault. Negative TEC anomalies are seen on the southern side of the fault.

\subsubsection{Comparison of Short-term Preseismic TEC Changes With Other Earthquakes}

[27] Figure 8 compares preseismic TEC anomalies derived in this study (the lnng station, satellite 27) with those before three M9 class mega-thrust earthquakes and the 1994 Hokkaido-Toho-Oki earthquake $\left(M_{w}\right.$ 8.3) reported in Heki [2011]. The amplitude of the anomaly of the 2007 Bengkulu earthquake is a little larger than the 2010 Maule earthquake, 
(a)

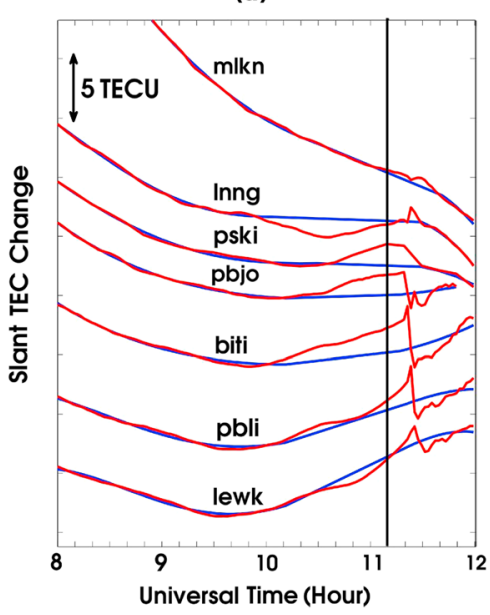

(c)

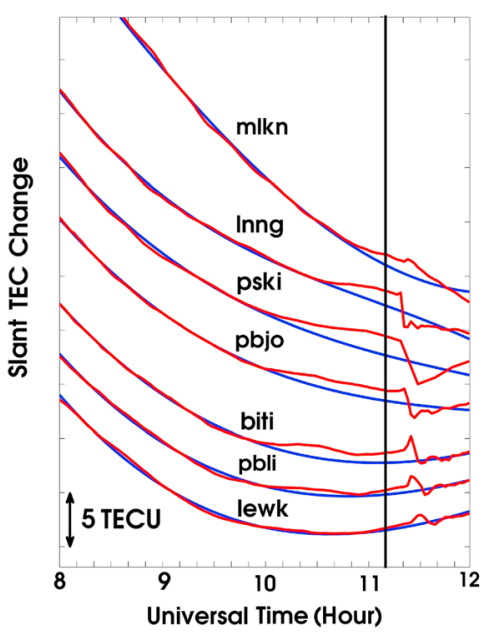

(e)

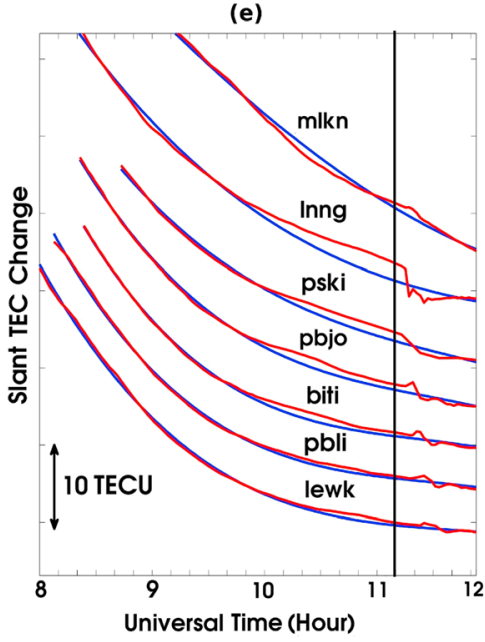

(b)

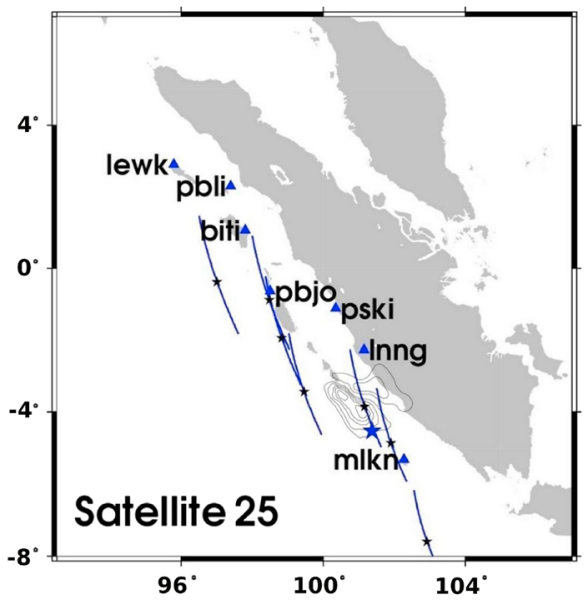

(d)

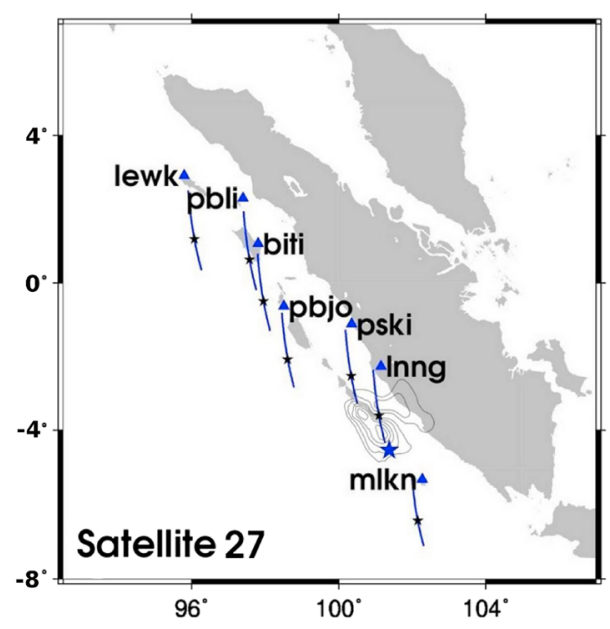

(f)

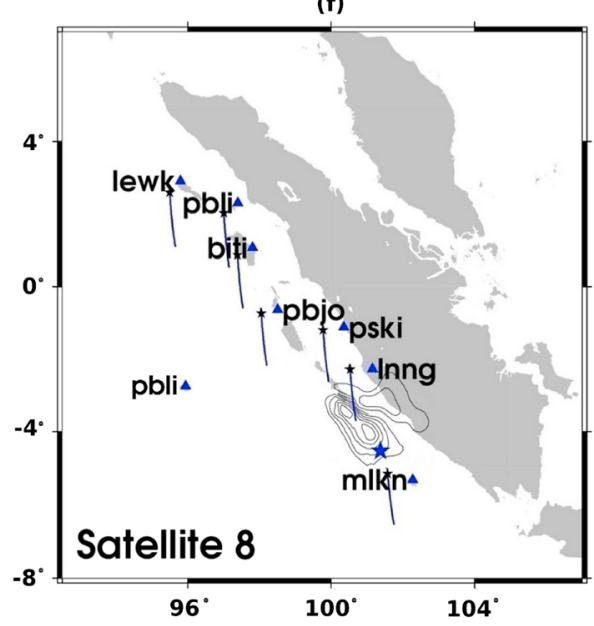

Figure 6. Slant TEC change time series taken at seven GPS stations with satellites (a, b) 25, (c, d) 27, and $(\mathrm{e}, \mathrm{f}) \mathrm{8}$. Temporary positive TEC anomalies started 60-30 min before the earthquake and disappeared after the CID passages. Vertical gray lines are the 2007 Bengkulu earthquake occurrence time (11:10 UT). Black smooth curves are the models derived assuming vertical TEC changes as cubic polynomials of time (10.0-11.4 is excluded in estimating the model curves), and anomalies shown in Figure 7 are defined as the departure from the model curves. Shown on the map are the positions of the seven GPS stations (blue triangles) and their SIP trajectories 10.6-11.5 UT (the black stars indicate 11:10). Contours of the coseismic uplift are the same as in Figure 1. 
(a)

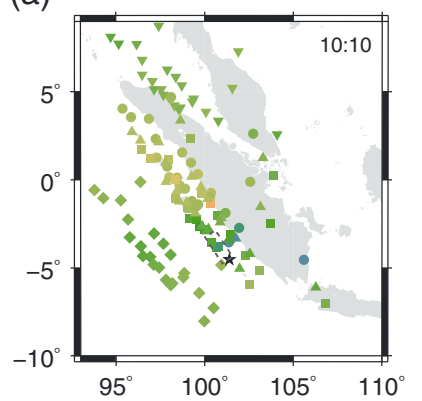

(b)

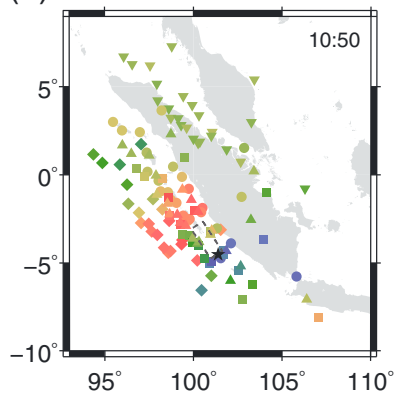

(c)

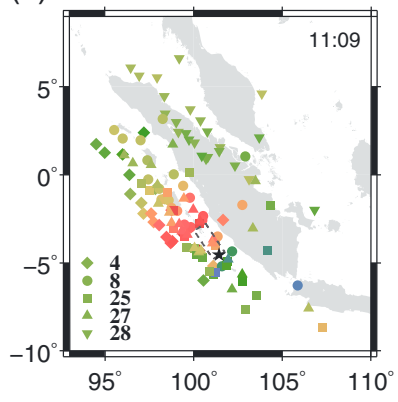

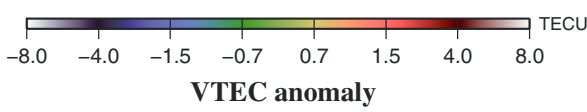

Figure 7. Vertical TEC anomalies at three time epochs, (a) $1 \mathrm{~h}$, (b) $20 \mathrm{~min}$, and (c) $1 \mathrm{~min}$ before the earthquake, observed at GPS stations with satellites 4, 8, 25, 27, and 28. Positive anomalies (red color) develop around the northern end of the ruptured fault (broken square) area while negative anomalies (blue color) are seen around the southern end.

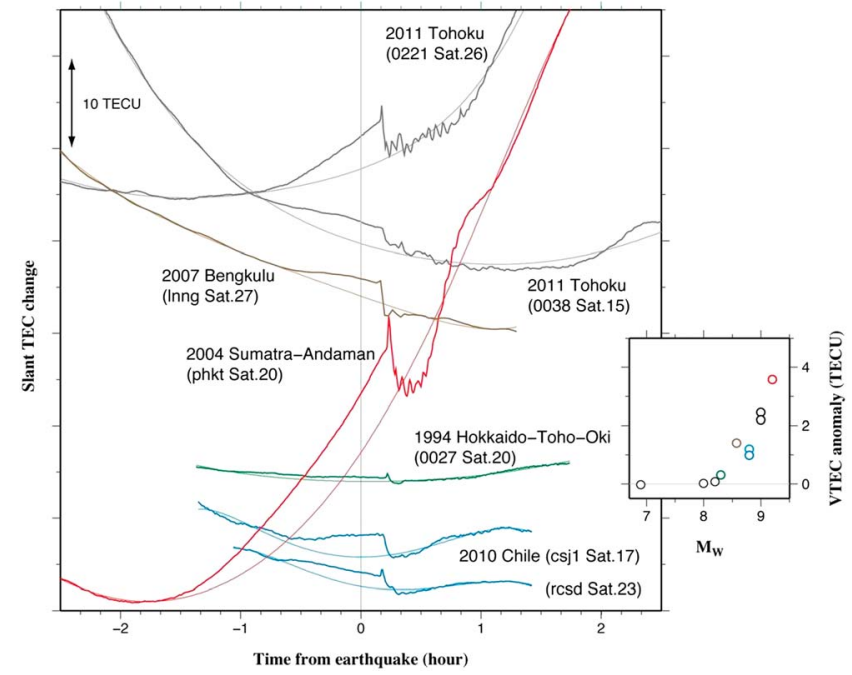

Figure 8. Preseismic TEC anomalies of the 2007 Bengkulu earthquake (brown) compared with other large earthquakes reported by Heki [2011]. The inset shows the dependence of the vertical TEC anomaly at the time of the earthquake occurrences on the moment magnitudes of the earthquakes (colors correspond to those of the TEC change curves).

and smaller than the 2011 Tohoku-Oki earthquake. It does not significantly deviate from the overall trend shown in the inset. Because of limited availability of GPS data, parameters other than earthquake magnitudes are nonuniform, e.g., background TEC and distance from the fault. However, these factors are not as important as the magnitude considering that the 1.0 difference in $M_{w}$ signifies the difference of a factor of 30 in the released energy (the horizontal axis of the Figure 8 inset spans over three orders of magnitudes in seismic energy). In contrast, background TEC and distances from faults do not vary that much (say, by a factor within 2 or 3 ) in the cases of Figure 8.

[28] There are no widely accepted models for such preseismic TEC anomalies. Kuo et al. [2011] suggested that rock current, as seen in laboratory experiments for stressed rocks [Freund, 2000], could change daytime TEC by $2-25 \%$. Concentration of such positive electric charges on the surface preceding the fault rupture might be a possibility. Recently, Enomoto [2012] proposed that the coupled interaction of earthquake nucleation with deep earth gases might be responsible for the preseismic anomaly in TEC.

[29] Next we discuss how often such TEC anomalies occur during days without earthquakes. In the supporting information (Figure S1), we plot the raw TEC changes and the best-fit cubic polynomials for the same combination of the GPS satellite (satellite 25) and the station (biti) over the 4 month period including the earthquake. We also show the Dst indices during this period to see geomagnetic activity. During periods of high geomagnetic activity, TEC often shows transient enhancements apparently similar to those seen in Figure 5 [Kil et al., 2011; Migoya-Oru'e et al., 2009; Ngwira et al., 2012]. Occurrences of typical geomagnetic storms are indicated by Dst indices $>70 \mathrm{nT}$ or $<-50 \mathrm{nT}[$ Oh and $Y i, 2011]$. The time series of this index show only small-scale disturbances around the earthquake day (day 255), and the TEC changes were moderate within a few days of the earthquake.

[30] The exception is the earthquake day, the only day out of the studied period when the TEC deviated by more than $3 \sigma$ from the model. Figure S2 shows the rootmean-squares (RMS) from individual curves obtained as the residuals from the models. The residuals of individual days show a normal distribution, and the largest RMS (0.84 TECU) corresponds to the earthquake day.

[31] We cannot completely rule out the possibility that space weather activity caused the anomaly on the earthquake day. Quiet geomagnetic conditions only mean that such probability is less than the case of earthquakes during geomagnetic storms (e.g., 2011 Tohoku-Oki earthquake). In fact, about $-3 \mathrm{nT}$ of change in the $z$ component of the interplanetary magnetic field (Bz) occurred on the day of the 2007 Bengkulu earthquake, which might have moved the $\mathrm{F}$ region plasma and changed TEC. In Figure S3, we plotted TEC changes in the same time window from six GPS stations with similar longitudes but different latitudes. They remain calm, except the CID signature of satellite 17 
Time in day 255 (UT hour)
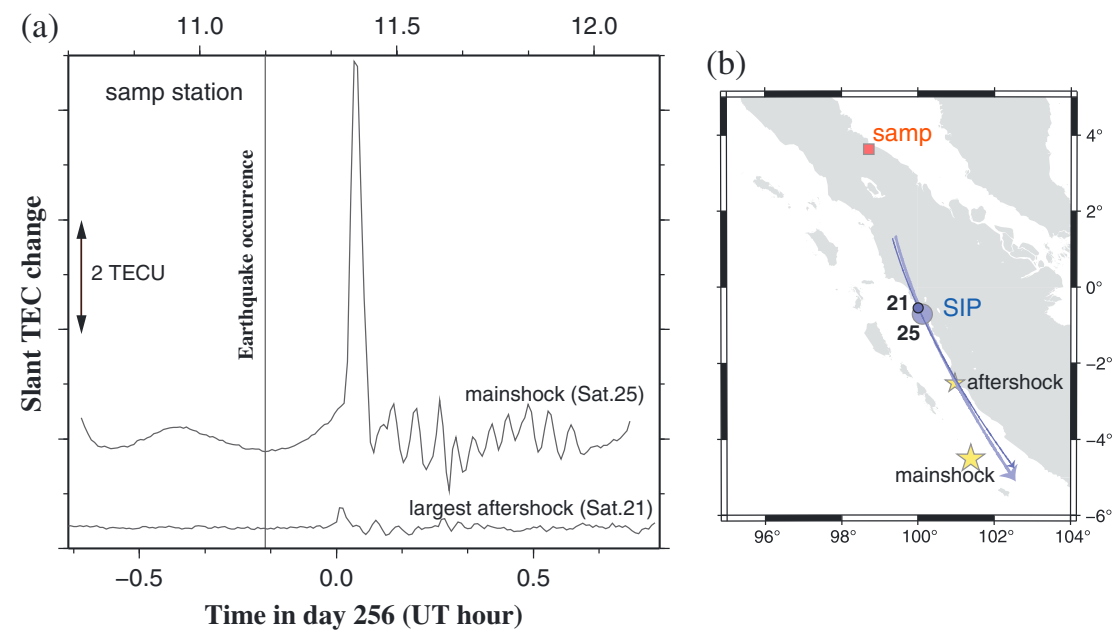

Figure 9. (a) Comparison of CIDs between the main shock (by satellite 25) and the largest aftershock (by satellite 21) at the samp station. The tracks of SIP for these satellites are shown in Figure 9b. The blue circles indicate the positions at the time of CID arrivals; they are very close to each other. The yellow stars show the epicenters. The difference between the CID amplitudes of the two earthquakes reflects those in magnitudes and the background TEC.

(a)

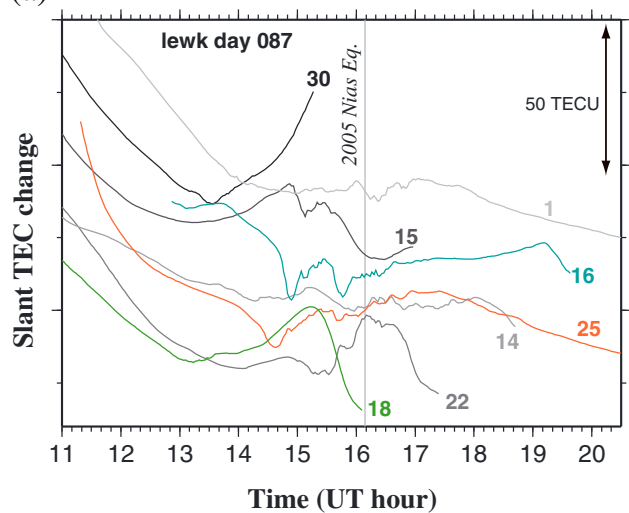

(b)

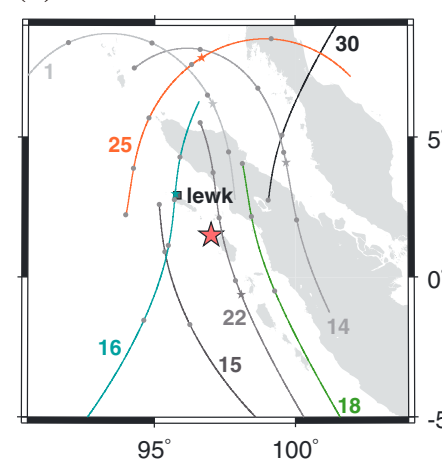

(c)

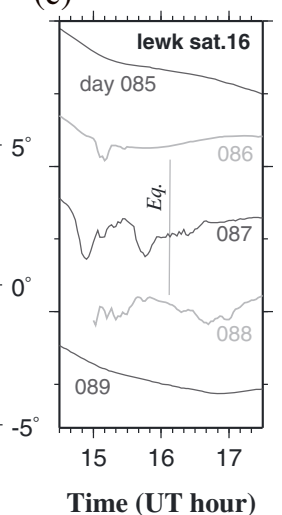

Figure 10. (a) Time series 11-21 UT of slant TEC changes observed at the lewk station. The plasma bubble signatures are severe around the black vertical line indicating the occurrence of the 2005 Nias earthquake (day 087, 16:09 UT). (b) Trajectories of SIP seen from the lewk station for the satellites shown in Figure 10a. On the trajectories, small black stars are SIP at 16:09 UT. The large red star denotes the epicenter. (c) Slant TEC changes over 5 consecutive days (days 085-089) obtained with satellite 16 from the lewk station. There, the vertical axis is the same as in Figure 10a.

in Christmas Island (XMIS), south of Sumatra, and severe scintillation signatures in an Antarctic station (CAS1). We repeated the same for six stations with similar latitudes (Figure S4), and found that there were no significant disturbances during the studied time window (at COCO, satellite 17 with the northernmost SIP possibly shows the preseismic TEC enhancement). Hence, we consider it rather unlikely that the observed preseismic changes are of space weather origin.

[32] What we should do in the future would be to study as many cases (i.e., mega-thrust earthquakes with available GPS data) as possible. If such anomaly occurred only before a part of these earthquakes (i.e., if some earthquakes are not preceded by short-term TEC anomalies), space weather may have caused them. On the other hand, if such an anomaly preceded every mega-thrust earthquake, it would be unlikely that space weather is responsible for every case.

\subsection{CID of the Largest Aftershock}

[33] Next we analyze the CIDs of the largest aftershock $\left(M_{w} 7.9\right)$ of the 2007 Bengkulu earthquake. It occurred later on the same day (12 September 2007 at 23:49:04 UTC) at the epicenter shown in Figure 9. The high-pass filtered (using degree-7 polynomials) slant TEC time series with satellite 21 observed at the samp station are compared with the similar time series at the same site for the main shock 
(satellite 25) in Figure 9a. The CID appeared $\sim 10$ min after this aftershock and was followed by small-amplitude TEC oscillations similar to the main shock case.

[34] Because of the similarity in the geometry of the station, satellites, and epicenters and in the focal mechanisms, they offer a rare opportunity to compare CID amplitudes between the two earthquakes. The main shock has the peak CID amplitude of $\sim 7$ TECU while that of the aftershock is only $\sim 0.3$ TECU. Such a large difference cannot be explained only by the difference in magnitude (seismic moment of the aftershock is $\sim 1 / 10$ of the main shock), and would be due also to the difference in the background TEC $(\sim 13$ TECU for the main shock and $<2$ TECU for the aftershock; see Figure 5). Since $M_{w} 7.9$ is not large enough to show preseismic TEC anomalies (Figure 8 inset), we will not discuss them.

\section{TEC Changes in the 2005 Nias Earthquake}

[35] Night-time ionosphere in equatorial regions often shows strong irregularities due to localized plasma density depletion known as plasma bubbles [Chu et al., 2005; $\mathrm{Li}$ et al., 2009]. Plasma bubbles often occur after sunset, triggered by Rayleigh-Taylor instability, and the probability of their occurrence becomes higher in spring and fall (around equinox) and during periods of high solar activity [Nishioka et al., 2007]. Their typical dimension is a few tens of kilometers in the EW direction and extends for thousands of kilometers in the NS direction along the geomagnetic field.

[36] The 28 March 2005 Nias earthquake $\left(M_{w} 8.6\right)$ was a little larger than the 2007 Bengkulu earthquake $\left(M_{w} 8.5\right)$. However, it occurred in the night time (23:09 in local time), one week after the vernal equinox, and before solar cycle 23 ended. These points suggest high probability of plasma bubble occurrences. Figure10a shows the raw slant TEC behavior 11-21 UT on the day of the 2005 Nias earthquake observed at the lewk station in Simeulue Island (Figure 10b). There we can see lots of quick decreases and increases, indicating the intersection of the line-of-sight measurements with plasma bubbles. Figure 10c compares the TEC changes during the same $3 \mathrm{~h}$ periods over 5 consecutive days before and after the 2005 Nias earthquake. It is interesting to see that they occurred not only on the day of the earthquake (day 087) but also on the days before (day 086) and after (day 088) the earthquake. This suggests that the observed plasma bubbles are not related to the earthquake but represent the normal behaviors of equatorial ionosphere in this time and season.

[37] Because plasma bubbles cause rapid changes in TEC much larger in amplitudes (tens of TECU) than earthquakegenerated signals (a few TECU), neither coseismic nor preseismic ionospheric disturbances can be recognized clearly. It is interesting to see that plasma bubble did not occur 2 days before (day 085) and after (day 089) the earthquake. TEC data immediately before and after the 2005 Nias earthquake are not suitable for any analyses of disturbances related to the earthquake.

\section{Conclusions}

[38] This paper provides the first comprehensive study of multiple aspects of CIDs and preseismic (both long- and short-term) ionospheric anomalies for two recent mega-thrust earthquakes in Indonesia. The studied aspects of CIDs include propagation speed (the observed velocity suggested its acoustic wave origin), azimuthal asymmetry of propagation, atmospheric resonance, polarity of the initial changes, and comparison of amplitudes between the main shock and the largest aftershock.

[39] A clear CID was found in the 2007 Bengkulu earthquake. Its apparent velocity suggested an acoustic wave origin. The earthquake is followed by a large aftershock that occurred $\sim 12 \mathrm{~h}$ later. This aftershock also showed CID signatures, and their smaller amplitudes can be explained by the difference in the earthquake magnitudes and the background TEC. These CIDs started with positive anomalies, similar to other reverse-fault earthquakes. The Rayleigh wave signatures were absent due possibly to the geometric alignment of the GPS network. The directivity (N-S asymmetry of propagation) of CIDs in the southern hemisphere was not clearly observed due to the N-S asymmetry of the network. Resonant oscillations of the atmosphere with a frequency of $\sim 5 \mathrm{mHz}$ were found to follow the CID and last for half an hour.

[40] Short-term preseismic TEC changes similar to the 2011 Tohoku-Oki earthquake were found in the 2007 Bengkulu earthquake. It was confirmed that geomagnetic activity was relatively quiet during the studied period. The behavior of TEC with the same satellite-station combination over 4 months suggests that the occurrences of similar anomalies are infrequent especially during geomagnetic quiescence. Hence, it is not likely that space weather is responsible for the observed short-term preseismic TEC changes. This, together with other cases [Heki, 2011], suggests that the observed anomaly is relevant to the earthquake. The physical mechanism of the preseismic TEC changes remains unclear in spite of several new studies. Long-term TEC precursors were not found.

[41] Plasma bubble occurred before and after the occurrence time of the 2005 Nias earthquake. Because their signatures were so strong, we could not even discuss the presence or absence of CIDs and preseismic TEC anomalies. Plasma bubbles were found on the previous and the next days and are considered to be irrelevant to the earthquake occurrence.

[42] Another large earthquake $\left(M_{w} 8.6\right)$ and its aftershock $\left(M_{w}\right.$ 8.2) occurred on 12 April 2012, within the subducting oceanic plate off northern Sumatra [Meng et al., 2012]. Considering its unique mechanism (one of the largest earthquakes with strike-slip mechanism), we have started to study its CID and preseismic TEC anomaly using the GPS data from the SUGAR network so that we can publish the results in the near future [Cahyadi and Heki, in preparation].

[43] Acknowledgments. We thank the team producing the GPS data of the SUGAR network. The reviews of the three anonymous referees improved the quality of the paper. MNC is supported by the Indonesian government fellowship (DIKTI scholarship).

\section{References}

Afraimovich, E. L., N. P. Perevalova, A. V. Plotnikov, and A. M. Uralov (2001), The shock-acoustic waves generated by earthquakes, Ann. Geophys., 19, 395-409.

Astafyeva, E., and K. Heki (2009), Dependence of waveform of near-field coseismic ionospheric disturbances on focal mechanisms, Earth Planets Space, 61, 939-943. 


\section{CAHYADI AND HEKI: IONOSPHERIC DISTURBANCES OF BENGKULU EARTHQUAKE}

Astafyeva, E., and K. Heki (2011), Vertical TEC over seismically active region during low solar activity, J. Atm. Terr. Phys., 73, 1643-1652.

Astafyeva, E., K. Heki, V. Kiryushkin, E. Afraimovich, and S. Shalimov (2009), Two-mode long-distance propagation of coseismic ionosphere disturbances, J. Geophys. Res., 114, A10307, doi:10.1029/2008JA013853.

Banerjee, P., F. F. Pollitz, and R. Bürgmann (2005), The size and duration of the Sumatra-Andaman Earthquake from far-field static offsets, Science, 308, 1769-1772.

Briggs, R. W. et al. (2006), Deformation and slip along the Sunda Megathrust in the great 2005 Nias-Simeulue earthquake, Science, 311, 1897-1901, doi:10.1126/science.1122602

Calais, E., J. B. Minster, M. A. Hofton, and H. Hedlin (1998), Ionospheric signature of surface mine blasts from Global Positioning System measurements, Geophys. J. Int., 132, 191-202.

Choosakul, N., A. Saito, Iyemori, T., and M. Hashizume (2009), Excitation of 4-min periodic ionospheric variations following the great Sumatra-Andaman earthquake in 2004, J. Geophys. Res., 114, A10313, doi:10.1029/ 2008JA013915.

Chu, F. D., J.-Y. Liu, H. Takahashi, J. H. A. Sobral, M. J. Taylor, and A. F. Medeiros (2005), The climatology of ionospheric plasma bubbles and irregularities over Brazil, Ann. Geophys, 23, 379-384.

Dautermann, T., E. Calais, J. Haase, and J. Garrison (2007), Investigation of ionospheric electron content variations before earthquakes in southern California, 2003-2004, J. Geophys. Res., 112, B02106, doi:10.1029/ 2006JB004447.

Enomoto, Y. (2012), Coupled interaction of earthquake nucleation with deep Earth gases: A possible mechanism for seismo-electromagnetic phenomena, Geophys. J. Int., 191, 1210-1214.

Freund, F. (2000), Time-resolved study of charge generation and propagation in igneous rocks, J. Geophys. Res., 105, 11001-11020, doi:10.1029/1999JB900423.

Gusman, A. R., Y. Tanioka, T. Kobayashi, H. Latief, and W. Pandoe (2010), Slip distribution of the 2007 Bengkulu earthquake inferred from tsunami waveforms and InSAR data, J. Geophys. Res., 115, B12316, doi:10.1029/2010JB007565.

Heki, K., and J.-S. Ping (2005), Directivity and apparent velocity of the coseismic ionospheric disturbances observed with a dense GPS array, Earth Planet. Sci. Lett., 236, 845-855.

Heki, K., Y. Otsuka, N. Choosakul, N. Hemmakorn, T. Komolmis, and T. Maruyama (2006), Detection of ruptures of Andaman fault segments in the 2004 great Sumatra earthquake with coseismic ionospheric disturbances, J. Geophys. Res., 111, doi:10.1029/2005JB004202.

Heki, K. (2006), Explosion energy of the 2004 eruption of the Asama volcano, Central Japan, inferred from ionospheric disturbances, Geophys. Res. Lett., 33, L14303, doi:10.1029/2006GL026249.

Heki, K. (2011), Ionospheric electron enhancement preceding the 2011 Tohoku-Oki earthquake, Geophys. Res. Lett. 38, L17312, doi:10.1029/ 2011GL047908.

Kakinami, Y. et al. (2012), Tsunamigenic ionospheric hole, Geophys. Res. Lett., 39, L00G27, doi:10.1029/2011GL050159.

Kil, H., L. J. Paxton, K.-H. Kim, S. Park, Y. Zhang, and S. J. Oh (2011), Temporal and spatial components in the storm time ionospheric disturbances, J. Geophys. Res., 116, A11315, doi:10.1029/2011JA016750.

Kuo, C. L., J. D. Huba, G. Joyce, and L. C. Lee (2011), Ionosphere plasma bubbles and density variation induced by pre-earthquake rock currents and associated surface charges, J. Geophys. Res., 116, A10317, doi: 10.1029/2011JA016628.

Le, H., J.-Y. Liu, and L. Liu (2011), A statistical analysis of ionospheric anomalies before 736 M6.0+ earthquakes during 2002-2010, J. Geophys. Res., 116, A02303, doi:10.1029/2010JA015781.

Li, G., B. Ning, L. Liu, W. Wan, and J.-Y. Liu (2009), Effect of magnetic activity on plasma bubbles over equatorial and low-latitude regions in East Asia, Ann. Geophys., 27, 303-312.
Liu, J.-Y., Y. I. Chen, Y. J. Chuo, and H. F. Tsai (2001), Variations of ionospheric total electron content during the Chi-chi earthquake, Geophys. Res. Lett., 28, 1383-1386.

Liu, J. Y. et al. (2009), Seismoionospheric GPS total electron content anomalies observed before the 12 May $2008 \mathrm{Mw} 7.9$ Wenchuan earthquake, J. Geophys. Res., 114, A04320, doi:10.1029/2008JA013698.

Mannucci, A. J., B. D. Wilson, D. N. Yuan, C. H. Ho, U. J. Lindqwister, and T. F. Runge (1998), A global mapping technique for GPSderived ionospheric total electron content measurements, Radio Sci., 33, 565-582.

Meng, L., J.-P. Ampuero, J. Stock, Z. Duputel, Y. Luo, and V. C. Tsai (2012), Earthquake in a maze: Compressional rupture branching during the $2012 \mathrm{M}_{\mathrm{w}}$ 8.6 Sumatra Earthquake, Science, 337, 724-726.

Migoya-Orué, O. Y., S. M. Radicella, and P. Coïsson (2009), Low latitude ionospheric effects of major geomagnetic storms observed using TOPEX TEC data, Ann. Geophys., 27, 3133-3139.

Molchanov, O. A., and M. Hayakawa (1998), VLF signal perturbations possibly related to earthquakes, J. Geophys. Res., 103, 17,489-17,504, doi:10.1029/98JA00999.

Moriya, T., T. Mogi, and M. Takada (2010), Anomalous pre-seismic transmission of VHF-band radio waves resulting from large earthquakes, and its statistical relationship to magnitude of impending earth-quakes, Geophys. J. Int., 180, 858-870.

Němec, F., O. Santolík, M. Parrot, and J. J. Berthelier (2008), Spacecraft observations of electromagnetic perturbations connected with seismic activity, Geophys. Res. Lett., 35, L05109, doi:10.1029/ 2007GL032517.

Ngwira, C. M., L.-A. McKinnell, P. J. Cilliers, and A. J. Coster (2012), Ionospheric observations during the geomagnetic storm events on 24-27 July 2004: Long-duration positive storm effects, J. Geophys. Res.,117, A00L02, doi:10.1029/2011JA016990.

Nishioka, M., A. Saito, and T. Tsugawa (2007), Occurrence characteristics of plasma bubble derived from global ground-based GPS receiver networks, J. Geophys. Res., 113, A05301, doi:10.1029/2007JA012605.

Oh, S. Y., and Y. Yi (2011), Solar magnetic polarity dependency of geomagnetic storm seasonal occurrence, J. Geophys. Res., 116, A06101, doi:10.1029/2010JA016362.

Ozeki, M. and K. Heki (2010), Ionospheric holes made by ballistic missiles from North Korea detected with a Japanese dense GPS array, J. Geophys. Res., 115, A09314, doi:10.1029/2010JA015531.

Rikitake, T. (1976), Earthquake Prediction, Elsevier, Amsterdam, pp. 357

Rolland, L. M., P. Lognonné, and H. Munekane (2011a), Detection and modeling of Rayleigh wave induced patterns in ionosphere, J. Geophys. Res., 116, A05320, doi:10.1029/2010JA016060.

Rolland, L. M., P. Lognonné, E. Astafyeva, E. A. Kherani, N. Kobayashi, M. Mann, and H. Munekane (2011b), The resonant response of the ionosphere imaged after the 2011 off the Pacific coast of Tohoku earthquake, Earth Planets Space, 63, 853-857.

Saito, A. et al. (2011), Acoustic resonance and plasma depletion detected by GPS total electron content observation after the 2011 off the Pacific coast of Tohoku Earthquake, Earth Planets Space, 63, 863-867.

Simons, W. J. et al. (2007), A decade of GPS in Southeast Asia: Resolving Sundaland motion and boundaries, J. Geophys. Res., 112, B06420, doi:10.1029/2005JB003868.

Tsugawa, T et al. (2011), Ionospheric disturbances detected by GPS total electron content observation after the 2011 off the Pacific coast of Tohoku Earthquake, Earth Planets Space, 63, 875-879.

Uyeda, S., and M. Kamogawa (2008), The prediction on two large earthquakes in Greece, Eos Trans. AGU, 89(39), doi:10.1029/ 2008EO390002.

Yao, Y. B., P. Chen, S. Zhang, J. J. Chen, F. Yan, and W. F. Peng (2012), Analysis of pre-earthquake ionospheric anomalies before the global $\mathrm{M}=7.0+$ earthquakes in 2010, Nat. Hazards Earth Syst. Sci., 12 $575-585$. 